\title{
Editorial \\ Implementación de los Acuerdos de Paz en Colombia
}

\author{
Mauricio Archila Neira* \\ DOI: https://doi.org/10.54118/controver.vi217.1245
}

\begin{abstract}
A casi cinco años de la firma del Acuerdo Final con las FARC-EP 4 para la construcción de una paz estable y duradera, la revista $\angle$ Controversia consideró oportuno convocar a la realización de balances ponderados sobre los logros y las dificultades en la implementación del Acuerdo en su conjunto o en algunos de los seis puntos pactados: 1) reforma rural integral; 2) participación política; 3) fin del conflicto; 4) solución al problema de las drogas ilícitas; 5) víctimas; y 6) implementación, verificación y refrendación.
\end{abstract}

Este interés se fundamenta en dos razones: primera, en que es paradójico que en el plano internacional estos acuerdos tengan gran reconocimiento, mientras en Colombia son materia de disputa y de polarización desde su firma, a lo que contribuyó la derrota, por estrecho margen, del plebiscito aprobatorio. Por ello su implementación ha sido un proceso tortuoso, pues además de los complejos trámites propios de la institucionalización de lo acordado, ha contado con la resistencia, cuando no la clara oposición, del actual Gobierno; y, segunda, en que para el CinEP la verificación de los compromisos establecidos en el Acuerdo Final es una tarea que ha adelantado periódicamente en estos años junto con el Centro de Recursos para el Análisis de Conflictos (CERAC), como partes que son de la Secretaría Técnica del Componente de Verificación Internacional (STCVI) de lo acordado. La convocatoria fue entusiastamente respondida y exigió una gran selección de la que salieron ocho artículos del dosier propuesto y dos de tema libre.

* Ph. D. en Historia, profesor titular de la Universidad Nacional de Colombia e investigador asociado del CinEP. Director y editor de la Revista Controversia. 
Precisamente el artículo que abre el tema central es autoría de la profesora Consuelo Corredor, coordinadora de la STCVI, y de Clara Ramírez, investigadora del tema rural en la misma Secretaria Técnica. En el texto, además de una necesaria contextualización internacional de los acuerdos y de ubicar allí las oportunidades que se abren, las autoras abordan los logros, dificultades y retos en la implementación de los seis temas acordados. Concluyen con unas oportunas alertas derivadas de la actual coyuntura y un recordatorio sobre las instancias de negociación para la realización de los mencionados acuerdos.

Por su parte, la reconocida investigadora de la Universidad Externado de Colombia, Consuelo Ahumada, hace una evaluación de dicha implementación desde el contexto internacional, ponderando especialmente las coincidencias entre los gobiernos de Obama y Santos, para impulsarla, y de Trump y Duque, para obstaculizarla. No en vano el título de su artículo habla del incierto entorno internacional para la paz en Colombia.

También desde el mundo académico, pero en este caso de cinco profesores de la Universidad Nacional de Colombia - Claudia Patricia Sierra, María Clemencia Castro, Jairo Ernesto Luna, David Alejandro Fresneda y Ana Milena Muñoz-, nos llegó otro balance de los acuerdos del Gobierno con las FARC-EP, atendiendo especialmente el proceso de reincorporación, para identificar sus alcances y limitaciones, todo con la finalidad de visualizar propuestas para su fortalecimiento en varios ejes planteados por los autores.

La también investigadora de la STCVI, Vera Samudio, y la internacionalista Alejandra Figueredo, ofrecen un acercamiento al derecho a la verdad en la justicia transicional, tema que según las autoras "generó uno de los debates más intensos en las negociaciones de La Habana”. Para ellas el derecho a la verdad tiene dimensiones éticas, jurídicas, políticas y fácticas. Es una verdad que se va construyendo relacionalmente en forma polifónica, y por ello va cambiando, dependiendo de las necesidades y problemas que enfrenta. Así se espera responder a la 
gran expectativa que esta verdad ofrece para la consolidación de la paz y la necesaria reconciliación.

Por su parte el politólogo Felipe Daza hace un balance "agridulce”, como él mismo lo sugiere, de la implementación de los puntos del Acuerdo Final con sus aciertos y tropiezos. Aunque termina siendo favorable a la perspectiva del gobierno de Santos, en los tres puntos que aborda -el agrario, la participación política y los cultivos de uso ilícito- aporta suficiente información para sustentar esta favorabilidad.

Hasta aquí incluimos los análisis de conjunto sobre los grandes temas acordados en 2016 con las FARC-EP. Los siguientes cuatro artículos se refieren a estudios de caso en los que se combina la reflexión académica con el trabajo etnográfico de campo. Esta sección la inaugura el historiador Wilson Pabón, quien se refiere a "los avatares" del espacio territorial de capacitación y reincorporación (ETCR) Antonio Nariño, en Icononzo (Tolima). Luego de un trabajo de campo de dos años, en el que realizó visitas a ese espacio e hizo entrevistas a sus integrantes y a los habitantes de la región de Sumapaz, nos ofrece una mirada ponderada del proceso de reinserción de los guerrilleros desmovilizados, en una región cercana a Bogotá y emblemática para la guerra y la paz en el país.

Algo similar hace la socióloga Diana Patricia González, pero para los ETCR de Pondores y Tierra Grata en la costa caribe colombiana. En este caso la autora destaca las estrategias de las mujeres excombatientes en su lucha por la reproducción material y simbólica de la vida colectiva, a pesar de los incumplimientos estatales y las muchas dificultades que enfrentan.

El último caso inscrito dentro del dosier es el de las comunidades campesinas de El Pato (Caquetá), realizado por el politólogo Juano Zuluaga. En un contrapunteo con lo ocurrido a nivel nacional, el autor muestra los claroscuros de la implementación del Acuerdo Final en el 
sur del país, resaltando la apropiación territorial y la construcción de democracia participativa desde abajo.

Por fuera del tema central — la implementación del Acuerdo con las FARC-EP - hay dos estudios que, sin embargo, lo tocan tangencialmente, pues dan luces sobre las violencias que reclaman una salida política. El primero es realizado por la conocida antropóloga Ximena Pachón y el sociólogo Óscar Cardozo, y versa sobre Rosalba Velásquez - la “Sargento Matacho"-, mujer guerrillera y madre desconocida originaria de Líbano (Tolima), a la que terminan reconociendo en tiempos recientes sus descendientes. De todo esto habla el artículo que se enmarca en el proyecto "Recuerdos de infancia de antiguos niños guerrilleros”, patrocinado por la Convocatoria Orlando Fals Borda 2018 de la Universidad Nacional de Colombia (UNAL).

Y esta universidad es precisamente el tema del último artículo de "tema libre", realizado por el historiador Esteban Roncancio y el autor de estas líneas. A partir de la elaboración de dos bases de datos sobre luchas universitarias y violencia en todas las sedes de la UNAL entre 1958 y 2018, se hace la reconstrucción histórica de lo ocurrido en el alma mater durante el conflicto armado colombiano. Es, por tanto, un aporte más a la construcción de la verdad liderada por la CEV (Comisión para el Esclarecimiento de la Verdad, la Convivencia y la no Repetición), surgida de los acuerdos de La Habana. 